\title{
Downregulation of DEPTOR inhibits the proliferation, migration, and survival of osteosarcoma through PI3K/Akt/mTOR pathway
}

\author{
Binwu $\mathrm{Hu}^{1, *}$ \\ Xiao Lv',* \\ Feng Gao' \\ Songfeng Chen ${ }^{2}$ \\ Shangyu Wang' \\ Xiangcheng Qing' \\ Jianxiang Liu' \\ Baichuan Wang' \\ Zengwu Shao' \\ 'Department of Orthopaedics, \\ Union Hospital, Tongji Medical \\ College, Huazhong University of \\ Science and Technology, Wuhan, \\ China; ${ }^{2}$ Department of Orthopaedic \\ Surgery, The First Affiliated \\ Hospital of Zhengzhou University, \\ Zhengzhou, China \\ *These authors contributed equally \\ to this work
}

This article was published in the following Dove Press journal:

OncoTargets and Therapy

8 September 2017

Number of times this article has been viewed
Abstract: Accumulating evidence reveals that DEP-domain containing mTOR-interacting protein (DEPTOR) plays pivotal roles in the pathogenesis and progression of many tumors. However, the expression level of DEPTOR and its function in the tumorigenesis of osteosarcoma (OS) remain unknown. In this study, we conducted quantitative real-time polymerase chain reaction, Western blot, and immunohistochemistry to detect DEPTOR expression level in human OS tissues and cell lines. To assess DEPTOR function, DEPTOR siRNA was designed and transfected into OS cells, which were then used in a series of in vitro assays. Our results indicated that DEPTOR was highly expressed in some OS tissues and cell lines. DEPTOR knockdown by siRNA dramatically inhibited cell proliferation, migration, invasion, and the formation of vasculogenic mimicry in OS cells. In addition, DEPTOR knockdown induced cell cycle arrest in the G0/G1 phase and apoptosis in the OS cell lines, MG63 and MNNG/HOS. Furthermore, we found that DEPTOR knockdown notably activated mTOR and inhibited the PI3K/Akt pathway. Taken together, these results suggest that DEPTOR overexpression is necessary for the proliferation, migration, invasion, formation of vasculogenic mimicry, and survival of OS cells and may be a potential target for the treatment of OS.

Keywords: osteosarcoma, DEPTOR, PI3K/Akt/mTOR pathway, proliferation, apoptosis

\section{Introduction}

Osteosarcoma (OS) is the most common malignant bone tumor with early metastatic potential and poor prognosis. ${ }^{1}$ Despite the fact that many patients benefit from multiagent chemotherapy and aggressive surgical resection, the survival rate of patients with OS did not improve over the past decades, especially for patients suffering from local recurrence or metastasis. ${ }^{2,3}$ Targeted therapy is considered a promising treatment for cancer. Many targeted drugs applied in the clinic are eutherapeutic. However, little progress has been made in the treatment of OS. ${ }^{4}$ Therefore, it is of great importance to identify novel therapeutic targets to improve the prognosis of patients with OS.

The mammalian target of rapamycin (mTOR), including mTORC1 and mTORC2, is an evolutionarily conserved serine/threonine protein kinase and the central regulator of cell metabolism, growth, proliferation, autophagy, survival, and angiogenesis because it responds to diverse cellular signals. ${ }^{5,6}$ Hence, deregulation of the mTOR pathway takes part in the pathogenesis of many diseases, including cancer, obesity, diabetes, and Alzheimer's disease. ${ }^{7,8}$ Abnormal activation of the mTOR pathway has been detected in OS, and accumulating evidence demonstrates that the aberrant activation of mTOR pathway plays a pivotal role in the proliferation, metastasis, apoptosis, and chemotherapy
Correspondence: Baichuan Wang:

Zengwu Shao

Department of Orthopaedics, Union

Hospital, Tongji Medical College,

Huazhong University of Science and

Technology, Wuhan 430022, China

Tel/fax +8602785805503

Email szwpro@163.com;

wangbaichuan-112@163.com
OncoTargets and Therapy 2017:10 4379-4391

(c) (1) (2) ๑ 2017 Hu et al. This work is published and licensed by Dove Medical Press Limited. The full terms of this license are available at https://www.dovepress.com/terms.php cc. hereby accept the Terms. Non-commercial uses of the work are permitted without any further permission from Dove Medical Press Limited, provided the work is properly attributed. For permision for commercial use of this work, please see paragraphs 4.2 and 5 of our Terms (https://www.doveppess. com/terms.php). 
resistance of OS cells. ${ }^{9}$ Thus, inhibiting mTOR pathway activation may be a promising target for OS treatment. Consistent with this notion, many studies confirmed that mTOR inhibitors, typically rapamycin, can effectively prevent the progression of OS. ${ }^{10}$ Furthermore, when combined with chemotherapy drugs, the antitumor curative effects of mTOR inhibitors are enhanced. ${ }^{11}$ However, the mTOR inhibitors applied for the treatment of OS are exiguous. Therefore, exploring new mTOR inhibitors will be of great interest for OS treatment.

DEP-domain containing mTOR-interacting protein (DEPTOR) is a recently identified endogenous inhibitor of mTOR. It was initially identified as being overexpressed in a subset of multiple myeloma (MM) cells. ${ }^{5}$ As a part of mTORC1 and mTORC2, DEPTOR inhibits both mTORC1 and mTORC2 through its PDZ domain. ${ }^{12}$ Meanwhile, mTOR can also negatively regulate DEPTOR expression at the transcriptional and posttranslational levels. ${ }^{5}$ Considering the inextricable connection between DEPTOR and mTOR complexes, DEPTOR is considered important in the pathogenesis of many diseases, especially in cancer. Accordingly, the abnormal expression of DEPTOR is detected in many tumors, and an interesting study suggested that DEPTOR is involved in cell growth, apoptosis, autophagy, and drug resistance of human cancers. ${ }^{13}$ However, the effect of DEPTOR on tumorigenesis is still controversial because the expression of DEPTOR varies depending of the tumor type. Previous studies show that DEPTOR is downregulated in pancreatic ductal adenocarcinoma, esophageal squamous cell carcinoma, colorectal cancer, and lung adenocarcinoma and indicates quick tumor progression and poor prognosis. ${ }^{14-17}$ In contrast, DEPTOR is overexpressed in multiple myeloma, cervical cancer, ovarian cancer, thyroid carcinoma, and T-cell leukemia, where it is essential for Akt activation and cell survival. ${ }^{5,6,18-20}$ Nevertheless, the role of DEPTOR in the tumorigenesis and progression of OS has not been elucidated. Thus, exploring the effect of DEPTOR on OS will be of great benefits and may provide new targets for OS treatment.

In this study, we first evaluated the expression of DEPTOR in human OS tissues and cell lines. Furthermore, we detected the specific effects of DEPTOR on OS cells. Finally, we explored the possible mechanism involved in this process. Our study revealed important functions of DEPTOR in human OS for the first time.

\section{Materials and methods Cell lines and tissues}

Human OS cells, MG63, MNNG/HOS, U2OS, and normal osteoblast cells hFOB1.19, were purchased from the Cell
Bank of Type Culture Collection of Chinese Academy of Sciences (Shanghai, China). Five OS tissue samples and paired adjacent normal tissue samples were obtained from patients undergoing neoadjuvant chemotherapy and surgery in the Department of Orthopaedic Surgery, Union Hospital (Wuhan, China). All samples used in this study were obtained in accordance with the policies of the institutional review board of the hospital. Ethical approval for the study was provided by the independent ethics committee, the Tongji Medical College, Huazhong University of Science and Knowledge, and written informed consent was obtained from each patient prior to the start of this study. Tissue samples were immediately stored in liquid nitrogen.

\section{Cell culture}

The osteoblasts, hFOB1.19 cells, were cultured in DMEM/ Ham's F-12(DMEM/F-12; Thermo Fisher Scientific, Waltham, MA, USA) containing 10\% fetal bovine serum (FBS; Sciencell, Carlsbad, CA, USA) and $0.3 \mathrm{mg} / \mathrm{mL} \mathrm{G418.} \mathrm{The}$ MG63 and MNNG/HOS cell lines were grown in Eagle's minimum essential medium (Thermo Fisher Scientific) containing 10\% FBS (Sciencell). The U2OS cells were cultured in RPMI medium 1640 (Thermo Fisher Scientific) supplemented with 10\% FBS (Sciencell). Cells were incubated at $37^{\circ} \mathrm{C}$ in a humidified atmosphere consisting of $5 \%$ $\mathrm{CO} 2$ and $95 \%$ air

\section{Synthetic DEPTOR siRNA and transfection}

Human DEPTOR si-RNAs and the corresponding negative control were designed and manufactured by RiboBio Co (Guangzhou, China). OS cells were treated with three independent DEPTOR siRNAs, the sense and antisense sequences of which are as follows: DEPTOR siRNA-1: 5'-CAUGACAAUCGGAAAUCUA dTdT-3', 3'-dTdTGU ACUGUUAGCCUUUAGAU-5'; DEPTOR siRNA-2: 5'-GCCAUGACAAUCGGAAAUCUA dTdT-3', 3'-dTdTU AGAUUUCCGAUUGUCAUGGC-5'; DEPTOR siRNA-3: 5'-GCAAGGAAGACAUUCACGAUU dTdT-3', 3'-dTdTG CAAGGAAGACAUUCACGAUU-5' ${ }^{\prime}$. The siRNA efficacy was tested and DEPTOR siRNA-1 was chosen to conduct the following experiments. Transfection was performed with Lipofectamine 3000 (Thermo Fisher Scientific) at the concentration of $120 \mathrm{nM}$ according to the manufacturer's instructions. The transfection medium was replaced with complete growth medium after $24 \mathrm{~h}$ of transfection, and the transfected cells were digested and cultivated in plates for further study. 


\section{Cell proliferation assay}

Cell proliferation was measured by using the cell counting kit 8 (CCK-8; Dojindo, Kyushu Island, Japan) following the manufacturer's instructions. In brief, $5 \times 10^{3} \mathrm{MG} 63$ or MNNG/ HOS cells were seeded in 96-well plates supplied with complete growth medium without antibiotics and transfected with nonspecific siRNA or DEPTOR siRNA; for each group, 10 replicates were set. Cell growth was detected every $24 \mathrm{~h}$ during 1-5 days of culture. The absorbance was measured after incubation for $3 \mathrm{~h}$ at $37^{\circ} \mathrm{C}$ at a wavelength of $450 \mathrm{~nm}$ on a microplate reader (Biotek, Winooski, VT, USA). All experiments were repeated at least three times.

\section{Colony formation assay}

To evaluate the anchorage-independent ability of OS cells, the colony formation assay was used. OS cells transfected with nonspecific siRNA or DEPTOR siRNA were trypsinized into a single-cell suspension $24 \mathrm{~h}$ after transfection and the cells were seeded in six-well plates at a concentration of $1 \times 10^{3}$ cells per well. After they were cultured for $\sim 2$ weeks, the cell colonies were fixed with $4 \%$ paraformaldehyde and stained with crystal violet (Sigma-Aldrich, Steinheim, Germany). Then, the colonies were photographed and counted.

\section{Wound healing assay}

For wound healing assay, cells transfected with nonspecific siRNA or DEPTOR siRNA were seeded in six-well plates and the wound was not made until the cells reached $90 \%$ confluence. The cell monolayer was carefully scratched using a sterile $1,000 \mu \mathrm{L}$ pipette tip. The detached cells were washed twice with PBS, and the medium was subsequently replaced with complete medium without FBS. The wound location was marked by three parallel lines, and the cells were monitored over a $48 \mathrm{~h}$ period and imaged at 0,24 , and $48 \mathrm{~h}$. The percentage of wound closure (original width - width after cell migration/original width) was calculated. ${ }^{21}$

\section{Transwell migration assay}

To further evaluate the influence of DEPTOR on the migration capacity of OS cells, we conducted the Transwell migration assay. Cells transfected with nonspecific siRNA or DEPTOR siRNA were starved for about $24 \mathrm{~h}$; then, $1.5 \times 10^{4}$ cells in serum-free medium were placed on the upper part of a Transwell chamber (Corning Costar, Rochester, NY, USA) and $20 \%$ FBS-medium was added in the lower chamber. After $48 \mathrm{~h}$ of incubation, the nonmigratory cells were removed by wiping with a cotton swab. The migratory cells were then fixed with $4 \%$ formaldehyde and stained with crystal violet.
Five visual fields of each insert were randomly chosen, and the migratory cells were counted under a light microscope.

\section{Tube formation assay}

To assess the influence of DEPTOR on the formation of vasculogenic mimicry (VM), the Matrigel tube formation assay was performed. ${ }^{22}$ In brief, $50 \mu \mathrm{L}$ Matrigel (BD Biosciences, San Jose, CA, USA) was added to 96 -well plate at $4^{\circ} \mathrm{C}$ and allowed to solidify at $37^{\circ} \mathrm{C}$ for $0.5 \mathrm{~h}$. Then, after transfection for $24 \mathrm{~h}, 2 \times 10^{4}$ MG63 or MNNG/HOS cells suspended in $100 \mu \mathrm{L}$ medium were seeded into the Matrigel-coated 96-well plate and incubated at $37^{\circ} \mathrm{C}$. The formation of capillary-like tubes was photographed at $1,3,6,12$, and $24 \mathrm{~h}$ after seeding. Quantitative analysis of the mean number of tube-like structures from six randomly chosen areas in 3D culture was performed. Data were expressed as the mean \pm SD from three independent experiments.

\section{Invasion assay}

Cell invasion was detected by the Transwell assay. In brief, $7 \times 10^{4}$ cells transfected with nonspecific siRNA or DEPTOR siRNA were suspended in serum-free medium and placed on the upper part of a Matrigel-coated invasion Transwell chamber (Corning Costar) and 20\% FBS-medium was added in the lower chamber. After $20 \mathrm{~h}$ of incubation for MNNG/HOS cells and $48 \mathrm{~h}$ of incubation for MG63 cells, the noninvading cells were removed by wiping with a cotton swab. The invading cells were then fixed with $4 \%$ formaldehyde and stained with crystal violet. Five visual fields of each insert were randomly chosen, and the invading cells were counted under a light microscope.

\section{Flow cytometry analysis}

Apoptosis of OS cells was measured using Annexin V-fluorescein isothiocyanate/propidium iodide (Nanjing Keygen Biotech, Nanjing, China) double staining. After transfection for $48 \mathrm{~h}$, the OS cells were harvested and washed twice with PBS. The cells were then stained with a commixture, including $200 \mu \mathrm{L}$ of binding buffer, $5 \mu \mathrm{L}$ of fluorescein isothiocyanate-conjugated Annexin V, and $5 \mu \mathrm{L}$ of propidium iodide and subjected to flow cytometry (BD FACSCalibur). For cell cycle analysis, the cells were processed with Cell Cycle and Apoptosis Analysis Kit (Beyotime Biotechnology Co. Ltd., Nantong, China) according to the manufacturer's specifications. Quantitation of cell cycle distribution was performed using Multi-cycle Software (ModFit software). The percentage of cells in G0, G1, S, and G2 phases was calculated. 


\section{Immunohistochemistry}

Biopsy samples obtained from patients were fixed in $4 \%$ formalin and embedded in paraffin. Tissues were cut into $5 \mu \mathrm{m}$ thick sections, and immunohistochemistry staining was performed using the Vectastain ABC Kit (rabbit IgG; Vector Laboratories, Burlingame, CA, USA). The rabbit polyclonal antibody against DEPTOR (1:500) was purchased from Abcam (Cambridge, UK). Sections were developed with Diaminobenzidine (DAB) and counterstained with hematoxylin.

\section{Western blot analysis}

Total protein of tissue samples and cells was extracted by using radioimmunoprecipitation assay buffer (SigmaAldrich). The protein concentration was determined by using the BCA Protein Assay Kit (Beyotime Biotechnology Co. Ltd). Equivalent amounts of protein were electrophoresed in sodium dodecyl sulfate-polyacrylamide gel and transferred onto polyvinylidene difluoride membranes (EMD Millipore, Billerica, MA, USA). The polyvinylidene difluoride membranes were blocked with 5\% nonfat milk in Tris Buffered Saline with Twee buffer for $1 \mathrm{~h}$ and incubated overnight at $4^{\circ} \mathrm{C}$ with rabbit anti-DEPTOR polyclonal antibodies $(1: 2,000$; Abcam), rabbit anti-PI3K polyclonal antibodies (1:500; Proteintech Group, Inc., Wuhan, China), rabbit anti-Akt monoclonal antibodies (1:1,000; Cell Signaling Technology, Danvers, MA, USA), rabbit anti-p-Akt monoclonal antibodies (Ser473, 1:1,000; Cell Signaling Technology), rabbit antimTOR monoclonal antibodies (1:1,000; Cell Signaling Technology), rabbit anti-p-mTOR monoclonal antibodies (Ser2488, 1:1,000; Cell Signaling Technology), rabbit antieIF-4E-binding protein (anti-4E-BP1 antibodies, 1:1,000; Cell Signaling Technology), rabbit anti-p-4E-BP1 antibodies (Thr37/46, 1:1,000; Cell Signaling Technology), and mouse anti- $\beta$-actin monoclonal antibodies (1:8,000; Tianjin Sungene Biotech, Tianjin, China). Signals were detected using ElectroChemi-Luminescence detection reagent (EMD Millipore) following the manufacturer's instructions.

\section{RNA extraction and quantitative real-time polymerase chain reaction (qRT-PCR) analysis}

Total RNA was extracted from the tissue samples and cells using TRIzol (Thermo Fisher Scientific) according to the manufacturer's instructions. The corresponding cDNA was synthesized by using the reverse transcriptional kit (TaKaRa Bio, Tokyo, Japan). The expression level of DEPTOR was quantified by qRT-PCR on the Step One Plus Real-Time PCR system (Thermo Fisher Scientific) using SYBR PrimeScript RT-PCR Kit (TaKaRa Bio). The following primers were used: DEPTOR, forward: 5'-TCTAGCCCAAACAGCGACA-3' and reverse: 5'-ACTTGAATGCTTTAGAACCCC-3'; GAPDH, forward: 5'-ACTTGAATGCTTTAGAACCCC-3' and reverse: 5'-GAGCCCCAGCCTTCTCCAT-3'. GAPDH was regarded as an internal control and the data were analyzed by the $2^{-\Delta \Delta \mathrm{Ct}}$ method.

\section{Statistical analysis}

All experiments were repeated at least three times to ensure reproducibility. Results were presented as mean \pm SD and analyzed by using the GraphPad Prism V.6.00 software (GraphPad Software, Inc., San Diego, CA, USA). Statistical analysis was performed by using the Student's $t$-test or one-way analysis of variance. $P<0.05$ was considered significant.

\section{Results DEPTOR is highly expressed in tissues from patients with OS and in OS cell lines}

To exclude the possibility that DEPTOR overexpression was an artifact induced by in vitro culture propagation, five pairs of fresh OS tissues and adjacent normal tissues were used to detect DEPTOR expression levels by qRT-PCR. DEPTOR expression was higher (2-fold or more) in four out of five tumor specimens than in the adjacent normal tissues (Figure 1A). DEPTOR detection by immunohistochemistry further confirmed higher DEPTOR expression in OS tissues than in adjacent normal tissues (Figure 1B). Western blotting was also performed to analyze DEPTOR protein expression, which was strikingly increased in OS tissues compared with that in adjacent normal tissues (Figure 1C). These results indicate that DEPTOR may play an important role in the development and survival of OS. Then, DEPTOR expression was examined by qRT-PCR and Western blot in OS cell lines (MG63, U2OS, and MNNG/HOS) and a normal osteoblastic cell line, human normal osteoblast cells hFOB1.19 (Figure 1D). Among the three OS cells, DEPTOR expression was the highest in MG63 cells and the lowest in U2OS cells. Thus, we used MG63 and MNNG/HOS in our following experiments.

To further explore the functional role of DEPTOR in OS, we used a synthetic siRNA to downregulate DEPTOR expression in MG63 and MNNG/HOS cells. This siRNA oligonucleotide (DEPTOR siRNA-1) was validated in other cell lines and it inhibits DEPTOR expression. The relative level of DEPTOR mRNA was decreased by $\sim 80 \%$ in MG63 and MNNG/HOS cells following transfection with DEPTOR 
A

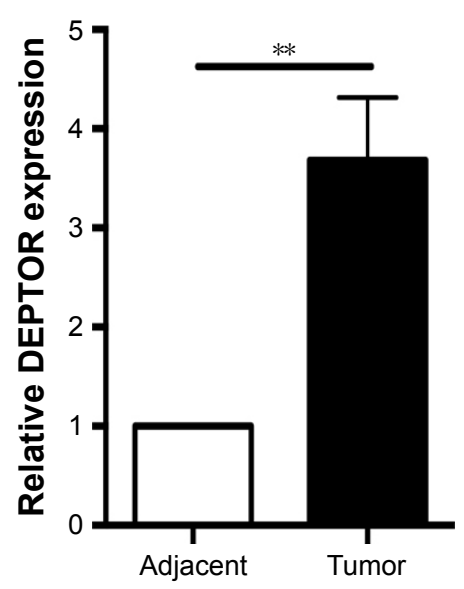

C

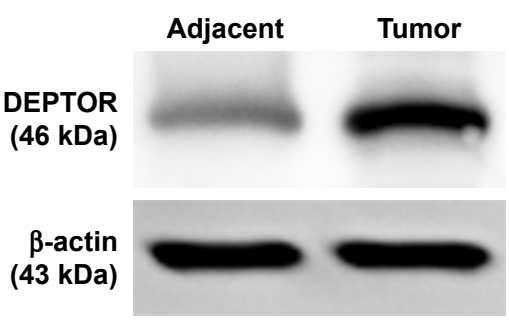

B
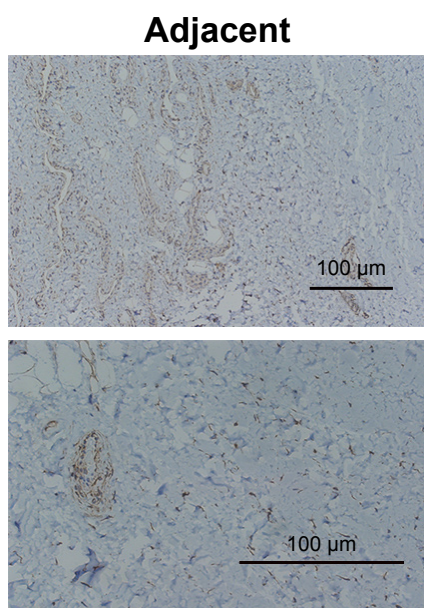

D

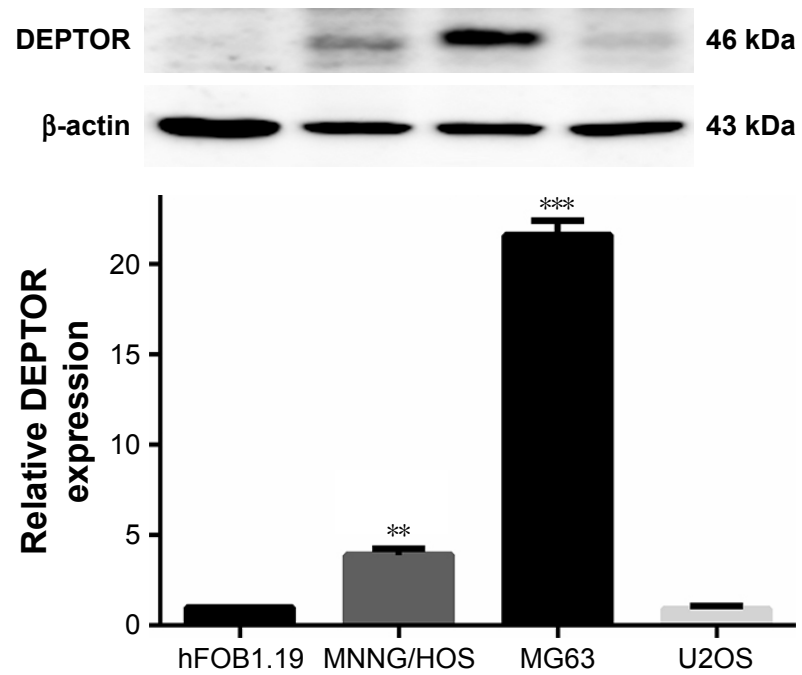

Figure I Quantitative RT-PCR, immunohistochemical staining, and Western blot analysis of DEPTOR expression in osteosarcoma tissues, corresponding adjacent normal tissues, and cell lines.

Notes: (A) qRT-PCR results of DEPTOR expression in osteosarcoma tissues and adjacent normal tissues. Results are presented as the fold change in tumor tissues relative to that in adjacent normal tissues within five pairs of cancer and adjacent tissues. (B) Immunohistochemical staining of DEPTOR expression in tumor samples and adjacent normal tissues. Original magnification: $\times 100$ (upper images), $\times 400$ (bottom images). (C) Western blot analysis of DEPTOR expression in tumor tissues and adjacent normal tissues; the results were normalized to $\beta$-actin expression. (D) Protein and mRNA expression of DEPTOR in different osteosarcoma cell lines and normal osteoblasts. qRT-PCR results are expressed as mean \pm SD of three independent experiments. Results are presented as the fold change in osteosarcoma cell lines relative to that in the osteoblastic cell line hFOBI.19 ( $* * P<0.0$ I, $* * * P<0.00$ I).

Abbreviations: DEPTOR, DEP-domain containing mTOR-interacting protein; $\mathrm{RRT}-\mathrm{PCR}$, quantitative real-time polymerase chain reaction.

siRNA when compared with nonspecific siRNA (Figure 2A). Western blotting indicated that DEPTOR protein level was also downregulated when cells were transfected with DEPTOR siRNA (Figure 2B).

\section{DEPTOR knockdown decreases the proliferation of OS cells}

Recent studies provided evidence of a decline in proliferation after DEPTOR siRNA transfection in some carcinomas. To examine the effects of DEPTOR knockdown on proliferation, CCK-8 assays were performed on MG63 and MNNG/HOS cell lines for 1-5 days, respectively. Transfection of DEPTOR siRNA dramatically inhibited MG63 and MNNG/HOS proliferation in a time-dependent manner
(Figure 2C and D). Subsequently, colony formation assay was performed to examine the anchorage-independent ability of MG63 and MNNG/HOS cells after DEPTOR siRNA transfection. In comparison to the nonspecific siRNA-transfected cells, DEPTOR siRNA dramatically repressed colony formation after 12 days (Figure $3 \mathrm{~A}$ and $\mathrm{B}$ ). These findings strongly confirmed that DEPTOR is necessary for OS proliferation. Therefore, we hypothesized that DEPTOR could be involved in the regulation of OS cell migration.

\section{DEPTOR knockdown compromises the migratory capacity of OS cells}

In order to test our hypothesis that DEPTOR regulates the migration of OS cells, wound healing assays, which provide 
A

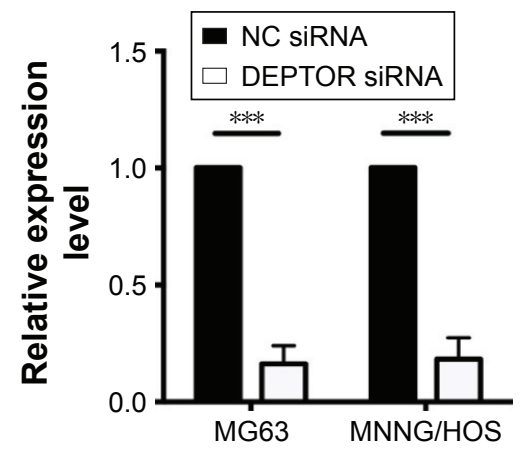

C

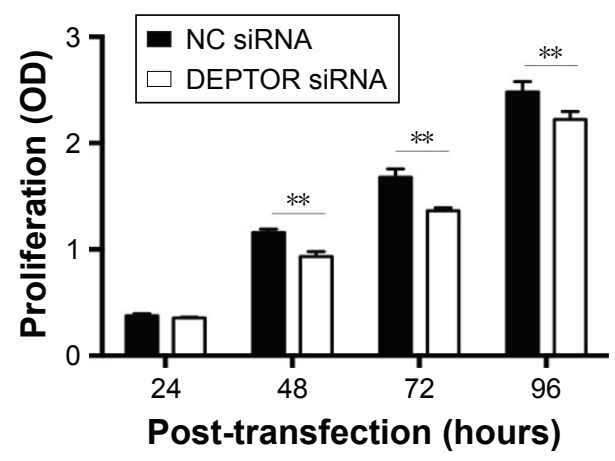

B

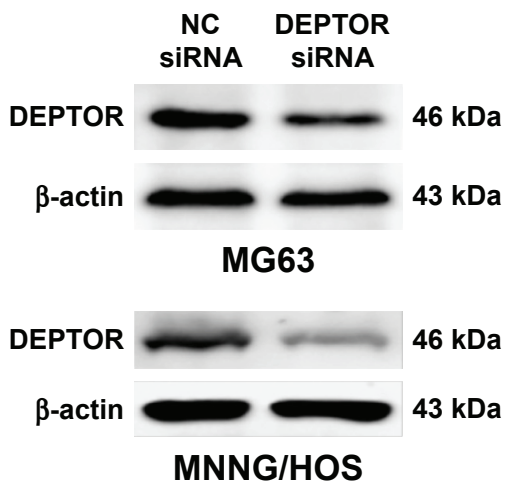

D

MNNG/HOS

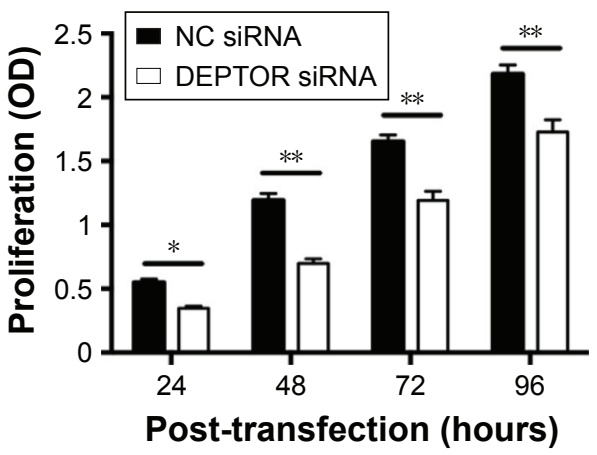

Figure 2 The DEPTOR siRNA efficacy and influence of DEPTOR knockdown on the proliferation of OS cells.

Notes: (A) Relative expression of DEPTOR mRNA in MG63 and MNNG/HOS cells after transfection with NC siRNA or DEPTOR siRNA for 24 h. Results are presented as the fold change in DEPTOR siRNA transfected cells relative to that in NC siRNA transfected cells. (B) Western blot analysis of DEPTOR protein when transfected with DEPTOR siRNA or NC siRNA in MG63 and MNNG/HOS cells. (C, D) The proliferation of MG63 (C) and MNNG/HOS (D) cells transfected with NC siRNA or DEPTOR siRNA. Data are expressed as mean $\pm S D$ of three independent experiments $(* P<0.05, * * P<0.01, * * * P<0.001$ compared with nonspecific siRNA group).

Abbreviations: DEPTOR, DEP-domain containing mTOR-interacting protein; NC siRNA, nonspecific siRNA; OS, osteosarcoma.

A

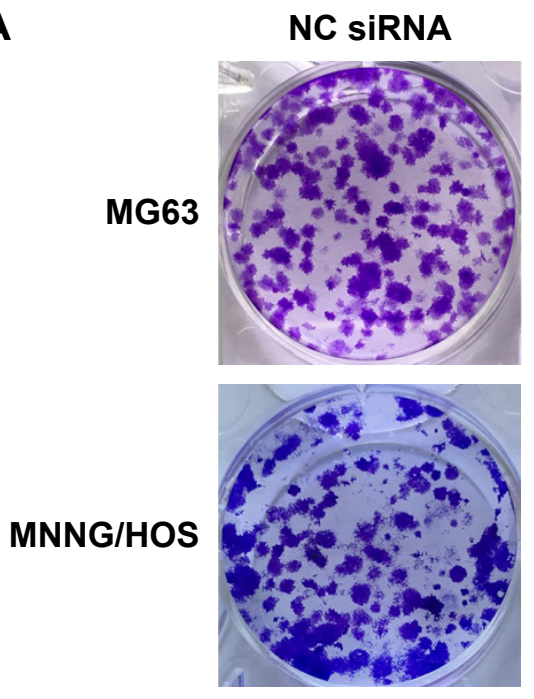

DEPTOR SIRNA
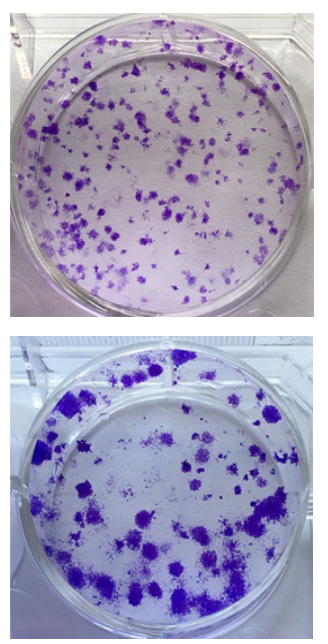

B

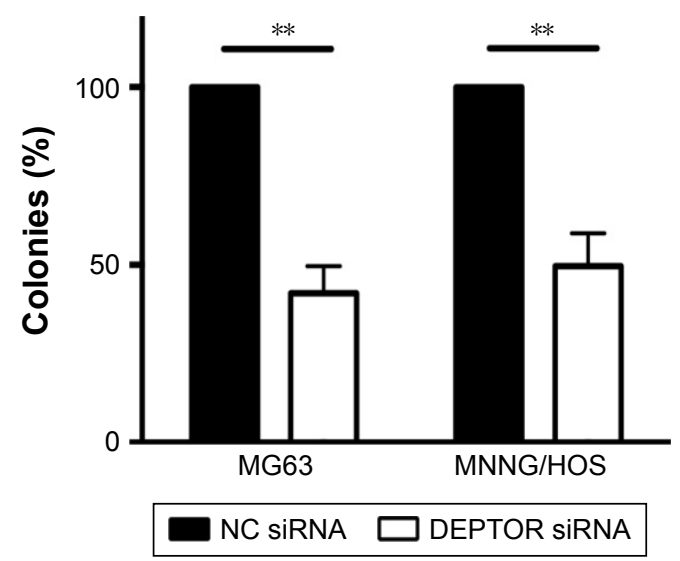

Figure 3 Colony formation capacity of osteosarcoma cells.

Notes: (A) Representative images of crystal violet staining of MNNG/HOS and MG63 cell colony formation assays. (B) Colonies containing $>50$ cells were counted. Quantified results were expressed as a percentage to the NC siRNA group, setting at $100 \%$. Data are expressed as mean \pm SD of three independent experiments (**P $<0.0$ I compared with NC siRNA group).

Abbreviation: NC siRNA, nonspecific siRNA. 
a visual indication of cell proliferative and migratory capacities spatially, were used in vitro. The ability of OS cells to close a wound gap was decreased in DEPTOR knocked down cells, compared with a marked migration into the wound in DEPTOR overexpressing cell lines (Figure 4A and B). To further confirm these results, the Transwell assay was also performed. The results indicated that the number of migratory OS cells sharply decreased in DEPTOR knocked down cells (Figure 4C and D). The results demonstrated that inhibition of DEPTOR decreased the migratory capacity of OS cell lines MG63 and MNNG/ HOS in vitro.

\section{DEPTOR knockdown decreases the VM formation and invasion capacity of OS cells}

$\mathrm{VM}$ is the formation of microvascular channels by malignant tumors. The presence of VM is considered an unfavorable prognostic factor in OS..$^{23,24}$ To determine whether DEPTOR influences the formation of VM in OS cells, we conducted the tube formation assay. Our results demonstrated that DEPTOR knockdown dramatically decreased the number of tube-like structures in MNNG/HOS cells. Although MG63 cells had limited capacity of formation of vascular mimicry during our experimental period, we still observed inhibition of tube
A

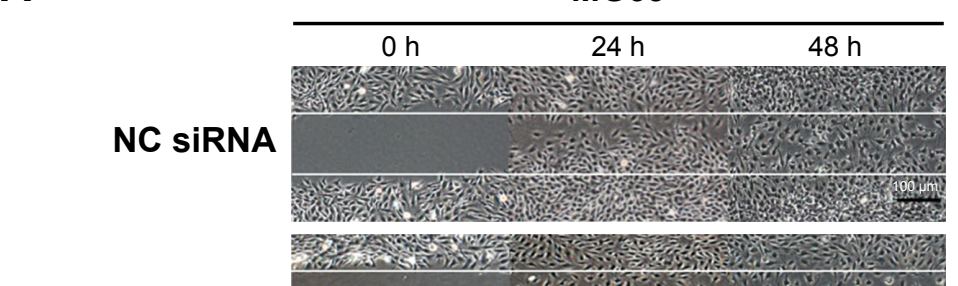

DEPTOR SIRNA
MNNG/HOS

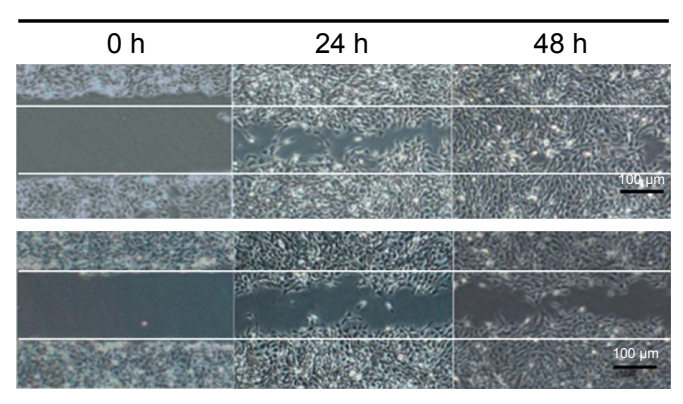

B

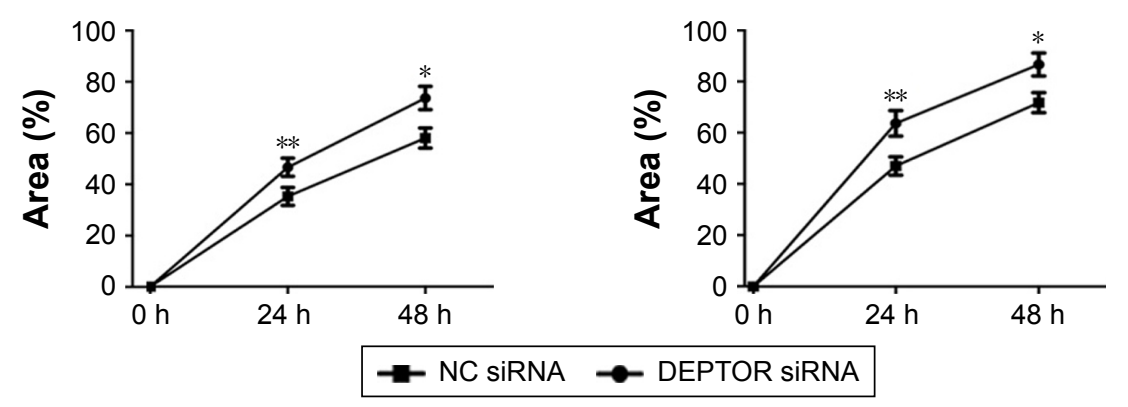

C
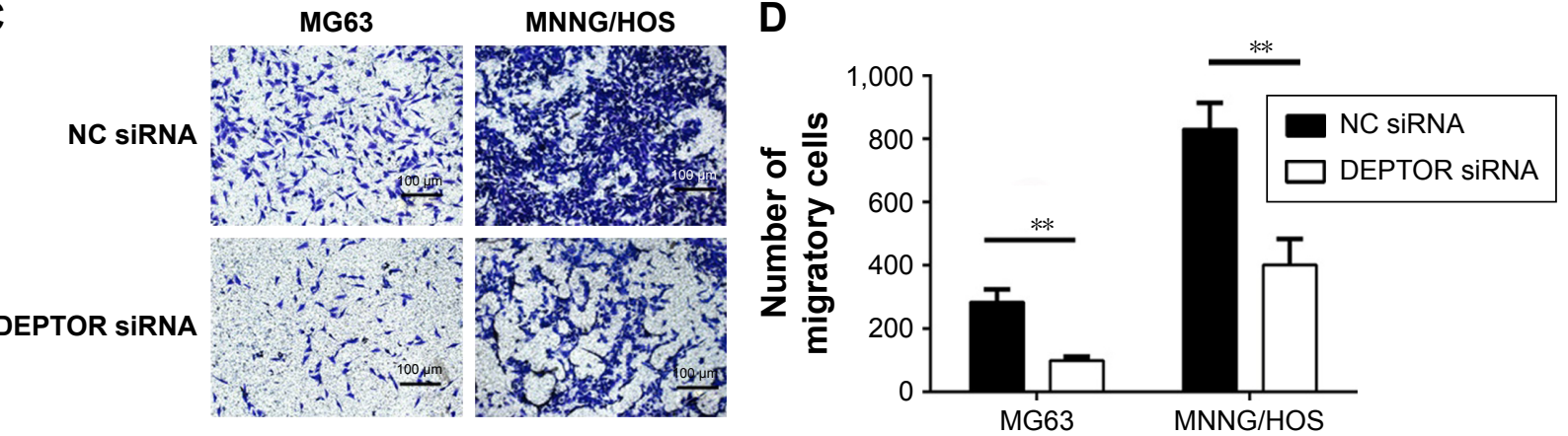

Figure 4 Influence of DEPTOR knockdown on the migratory capacity of osteosarcoma cells.

Notes: (A) Micrographs of wound healing assays for MNNG/HOS and MG63 cells transfected with NC siRNA or DEPTOR siRNA. Images were obtained at 0, 24, and $48 \mathrm{~h}$, original magnification: $\times 100$. (B) Percentage of wound closure. Data are expressed as mean \pm SD of three independent experiments. (C) Micrographs of the Transwell migration assay in the MNNG/HOS and MG63 cells, original magnification: $\times 100$. (D) Number of migratory cells. Data are expressed as mean \pm SD of three independent experiments $(* P<0.05, * * P<0.01$, compared with NC siRNA group).

Abbreviations: DEPTOR, DEP-domain containing mTOR-interacting protein; NC siRNA, nonspecific siRNA. 
A

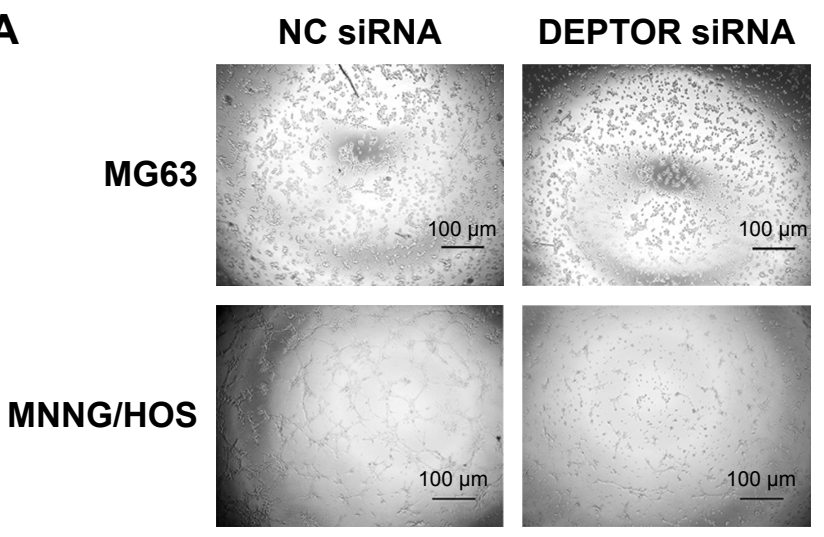

C

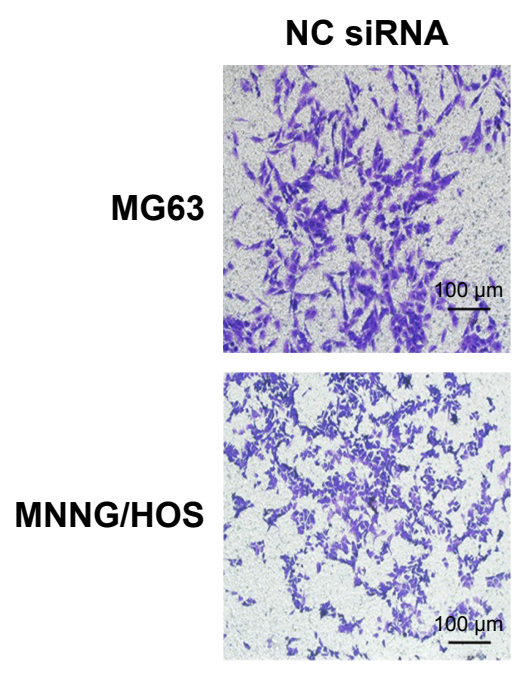

DEPTOR SIRNA
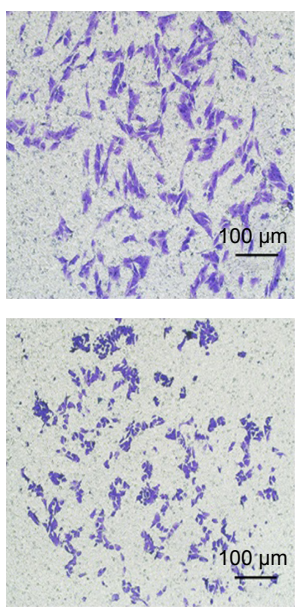

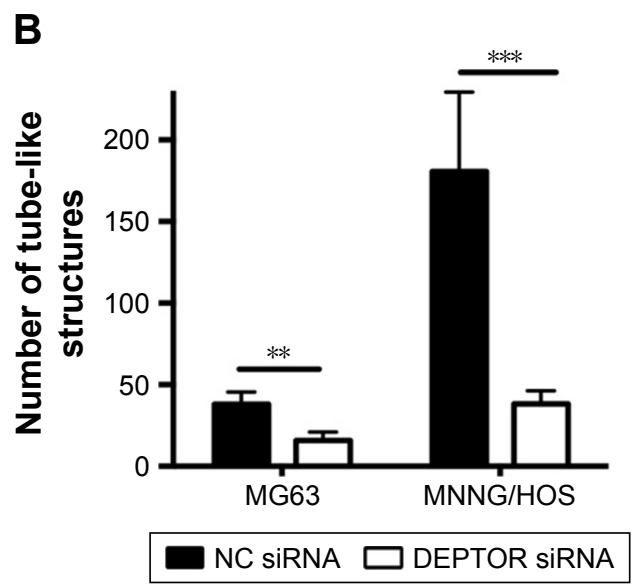

D

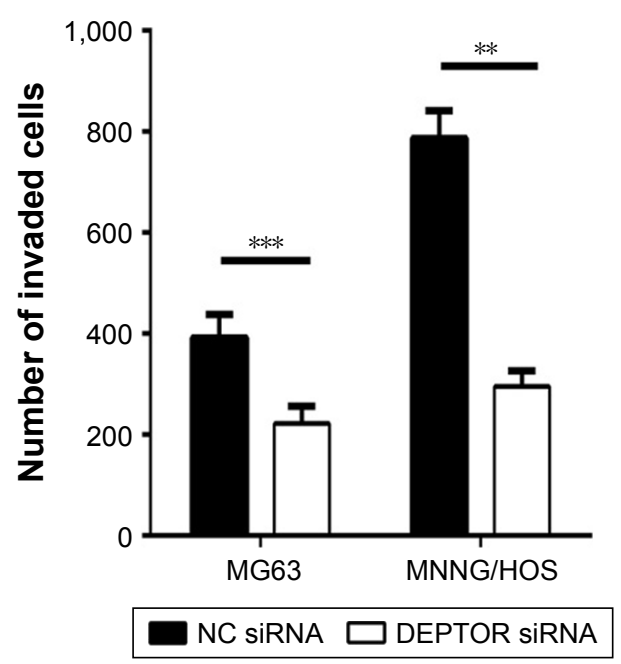

Figure 5 Effects of DEPTOR knockdown on the VM formation and invasion capacity of osteosarcoma cells.

Notes: (A) Images of tube-like structures in MNNG/HOS and MG63 cells transfected with NC siRNA or DEPTOR siRNA, original magnification: $\times$ I00. (B) Mean number of tube-like structures in MNNG/HOS and MG63 cells. Data are expressed as mean \pm SD of three independent experiments. (C) Micrographs of the Transwell invasion assay in the MNNG/HOS and MG63 cells, original magnification: $\times 100$. (D) Number of invaded cells. Data are expressed as mean $\pm S D$ of three independent experiments $(* * P<0.0$ I, $* * * P<0.001$ compared with nonspecifc siRNA group).

Abbreviations: DEPTOR, DEP-domain containing mTOR-interacting protein; NC siRNA, nonspecific siRNA; VM, vasculogenic mimicry.

formation in DEPTOR siRNA group (Figure 5A and B). Since DEPTOR knockdown could inhibit the migration and VM formation capacity of OS cells, we hypothesized that the invasion ability could also be decreased in DEPTOR knockdown cells. Accordingly, our experiment indicated that downregulation of DEPTOR markedly inhibited the invasion capacity of OS cell lines, MG63 and MNNG/HOS, in vitro (Figure 5C and D). Taken together, these data indicated that DEPTOR overexpression might contribute to the formation of VM and invasion in OS cells, leading to poor prognosis.

\section{DEPTOR knockdown induces cell cycle} arrest and apoptosis in OS cells

mTORC1 signaling plays a key role in the regulation of cell growth and protein translation. ${ }^{25}$ To determine whether
DEPTOR knockdown induced cell cycle arrest in OS cell lines, we performed a standard cell cycle assay by flow cytometry using MG63 and MNNG/HOS cells. DEPTOR knockdown promoted G0/G1 phase arrest in MG63 and MNNG/HOS cells. An increase of almost $20 \%$ of cells in the G0/G1 phase was detected for both cell lines. Meanwhile, DEPTOR knockdown led to a $14 \%$ and $16 \%$ decrease in the number of cells in the $\mathrm{S}$ phase, when compared with cells transfected with the nonspecific siRNA (Figure 6A and B). Altogether, these results suggest that DEPTOR knockdown prompts G0/G1 cell cycle arrest in OS cells. In addition, flow cytometry analysis of MG63 and MNNG/HOS cells also indicated that inhibition of DEPTOR caused an increase in the proportion of apoptotic cells in DEPTOR siRNA group in comparison with that in nonspecific siRNA 
A
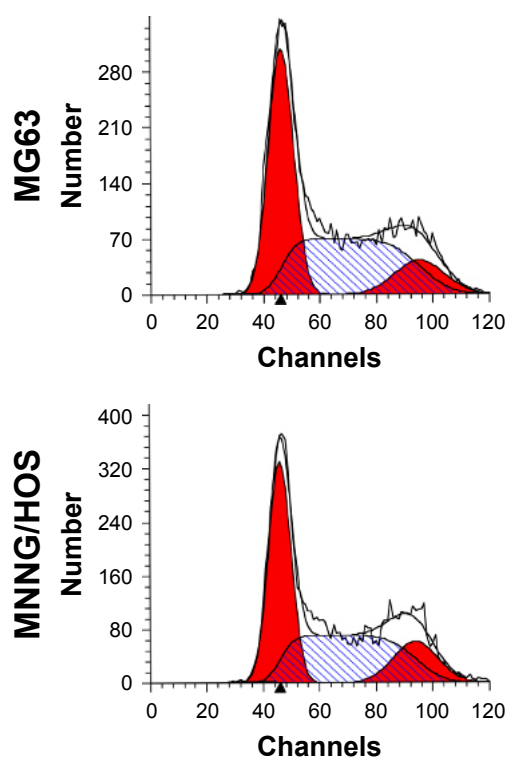

C

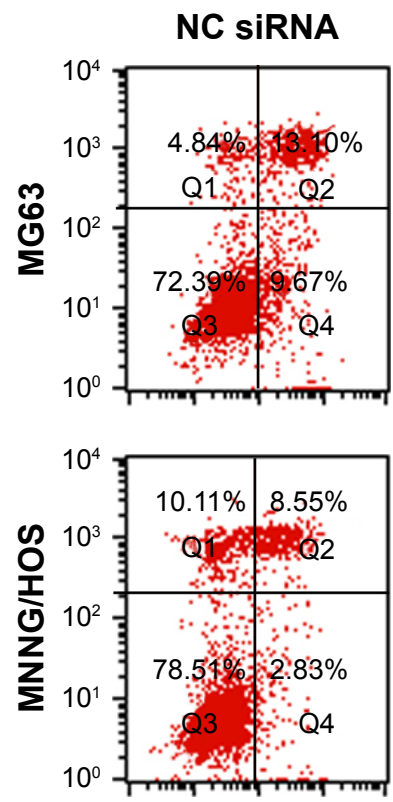

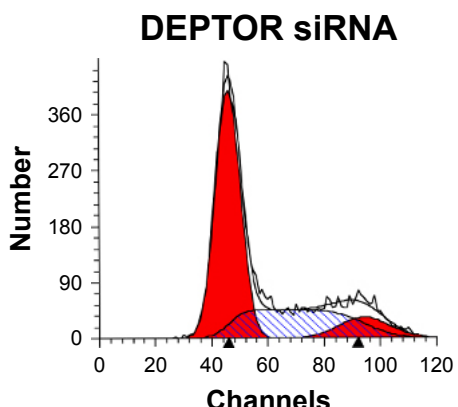

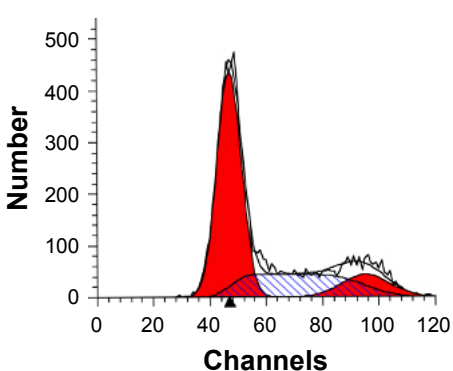

DEPTOR SIRNA
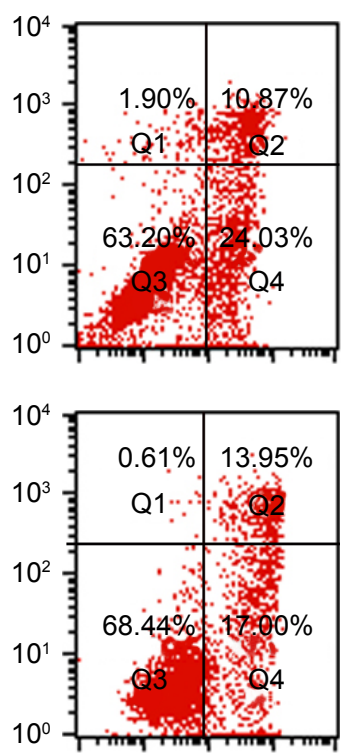

B MG63

MNNG/HOS

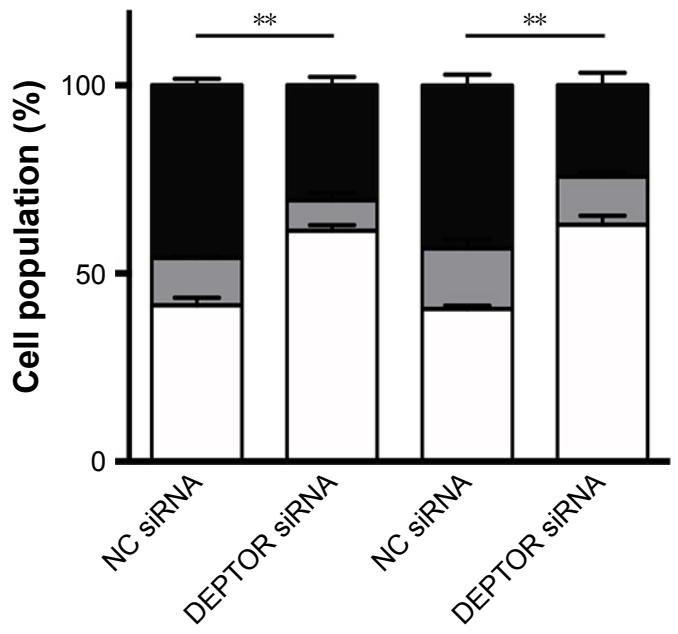

s $\square$ G2-M $\square$ G0-G1

D

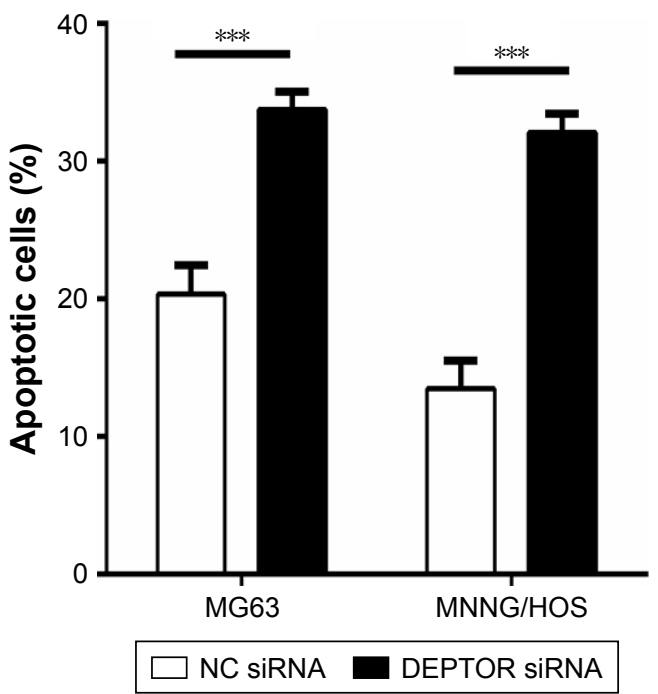

Figure 6 DEPTOR knockdown induced cell cycle arrest and apoptosis in osteosarcoma cells.

Notes: (A) Flow cytometric analysis of the percentage of cells transfected with NC siRNA or DEPTOR siRNA in various phases of the cell cycle. (B) Flow cytometric analysis of the percentage of cells in different phases of the cell cycle with three independent experiments. (C) Flow cytometric analysis of apoptotic cells by Annexin V-FITC/PI staining; in all four plots, the right upper and right lower quadrants show apoptotic cells. (D) The proportion of apoptotic cells in MG63 and MNNG/HOS cells. Data are expressed as mean $\pm S D$ of three independent experiments $(* * P<0.0$ I, $* * * P<0.00$ I compared with nonspecific siRNA group).

Abbreviations: DEPTOR, DEP-domain containing mTOR-interacting protein; FITC, fluorescein isothiocyanate; NC siRNA, nonspecific siRNA; PI, propidium iodide.

group (Figure 6C and D). Hence, we hypothesized that the inhibition of OS cell proliferation may be a synergetic effect of cell cycle arrest and apoptosis.

\section{DEPTOR overexpression promotes the progression of OS by inhibiting mTOR and activating the PI3K/Akt pathway}

DEPTOR regulates the activation of the PI3K/Akt pathway, which is responsible for other tumor suppressive functions. ${ }^{14}$
To clarify whether DEPTOR knockdown exerts its antitumor effects through this mechanism in OS, we performed Western blot to analyze the expression of key proteins in the PI3K/ Akt/mTOR pathway, PI3K, Akt, p-Akt, mTOR, p-mTOR, 4E-BP1, and p-4E-BP1. As an endogenous inhibitor of mTOR, the expression levels of mTOR, p-mTOR, 4E-BP1, and p-4E-BP1 were increased in DEPTOR knocked down cells, compared to that in control cells. Furthermore, DEPTOR knockdown reduced the expression levels of PI3K, Akt, 


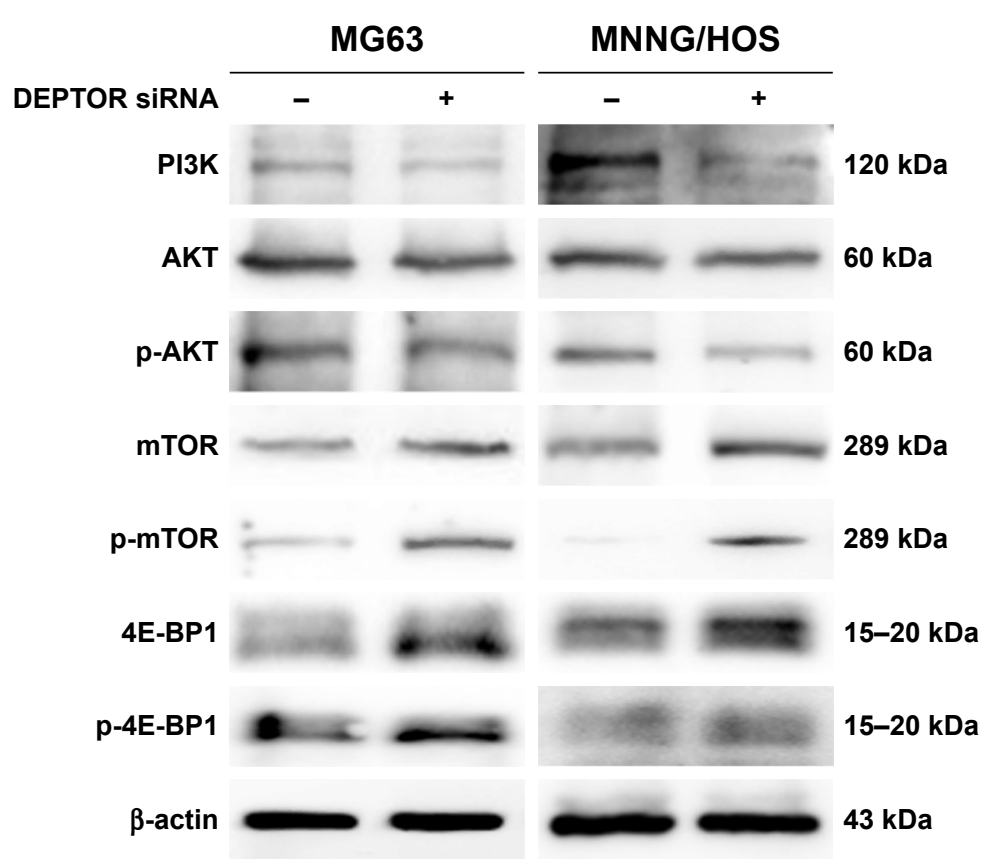

Figure 7 DEPTOR knockdown inhibits the progression of OS by regulating the PI3K/AKT/mTOR pathway.

Note: After $48 \mathrm{~h}$ of transfection, the expression levels of PI3K/AKT/mTOR pathway-related proteins, PI3K, AKT, p-AKT, mTOR, p-mTOR, 4E-BPI, and p-4E-BPI, were determined by Western blot.

Abbreviations: DEPTOR, DEP-domain containing mTOR-interacting protein; mTOR, mammalian target of rapamycin; OS, osteosarcoma.

and p-Akt to various degrees (Figure 7). These results indicate that the $\mathrm{PI} 3 \mathrm{~K} / \mathrm{Akt} / \mathrm{mTOR}$ pathway might be involved in DEPTOR-mediated tumorigenesis in OS.

\section{Discussion}

OS is the most common primary malignant bone tumor characterized by early metastasis and chemoresistance, and survival rates of patients with OS have not improved in recent years. Therefore, novel target chemotherapy drugs are urgently needed..$^{26}$ mTOR, a downstream mediator in the PI3K signaling pathway, is an evolutionarily conserved protein kinase, including two distinct multiprotein complexes, $\mathrm{mTORC} 1$ and $\mathrm{mTORC} 2$, that regulate basic biologic processes and tumorigenesis. ${ }^{27-30} \mathrm{mTORC} 1$ regulates cell growth through key regulators of protein synthesis, phosphorylating S6 kinase 1 and the 4E-BP1, whereas mTORC2 modulates cell survival in response to growth factors by phosphorylating its downstream effectors, Akt/PKB and SGK $1 .{ }^{31}$ Recently, many basic research studies and clinical trials focused on the aberrant activation of mTOR, which promotes proliferation and metastasis in human OS, resulting in the development of small synthetic inhibitors of the mTOR pathway. ${ }^{32-35}$ The detailed mechanism underlying the functions of the mTOR pathway and related inhibitors in OS cells remains unclear.

DEPTOR is a $46 \mathrm{kDa}$ mTOR-binding protein encoded by the DEPTOR gene located on the $8 \mathrm{q} 24$ region, which presents many single-nucleotide polymorphisms, and the genes involved in cancer susceptibility. ${ }^{36}$ As a natural inhibitor interacting with $\mathrm{mTORC} 1$ and $\mathrm{mTORC} 2$ complexes, the aberrant expression of DEPTOR induces cell growth, apoptosis, autophagy, and endoplasmic reticulum stress response. ${ }^{37-39}$ However, its functions have not been fully characterized. Especially, the biologic function of DEPTOR in tumorigenesis remains unclear, as DEPTOR could function as an oncogene or as a tumor suppressor depending on the specific type of tumor cells and environment. ${ }^{5}$ While there is a strong interest in the development of novel endogenous mTOR inhibitors such as DEPTOR in many other types of malignancy, little is known about the biologic functions and the mechanism underlying DEPTOR function in OS cells. Herein, we first report that DEPTOR expression is markedly higher in specimens from patients with OS and human OS cell lines, compared with adjacent benign tissues and osteoblast cells. In contrast with most solid cancers, in which DEPTOR expression is generally low, DEPTOR expression was high in OS tissues. These results are consistent with DEPTOR expression in some subtypes of breast cancer, prostate cancer, chronic myeloid leukemia, and MM. ${ }^{5,12,19,38,39}$ In one case, DEPTOR expression showed minor difference between the corresponding adjacent benign tissue and cancer tissue. In addition, DEPTOR mRNA and protein expression in one OS cell line, U2OS, was not as high as that observed in MG63 and MNNG/HOS cells. These results are consistent with 
previous studies reporting that DEPTOR could be overexpressed or downregulated in different tumors and even in the same tumor, DEPTOR could have various expression levels in different cell lines. ${ }^{5,40,41}$ In breast cancer, DEPTOR exerts a dual function. Downregulation of DEPTOR expression is essential for epithelial-mesenchymal transition and invasion, while upregulation of DEPTOR expression is fundamental for chemoresistant activities in metastatic lesions. ${ }^{40}$ These results show the complexity of DEPTOR regulation in different tissues and cell lines. MMs expressing high levels of DEPTOR are characterized by Ig gene translocation of c-MAF and MAFB transcription factors. c-MAF depletion induced a reduction in DEPTOR mRNA and protein expression in MM cells. High levels of DEPTOR expression maintain Akt activation and suppress phosphorylating S6 kinase 1 expression to relieve the feedback inhibition from mTORC1 in the PI3K pathway, whereas a reduction in DEPTOR expression causes cell apoptosis. ${ }^{5}$ This may explain the diversity in DEPTOR expression in different tissues and cell lines.

In this study, we elucidated the principal role of DEPTOR in OS carcinogenesis and the potential mechanism underlying DEPTOR function through DEPTOR knockdown. The level of DEPTOR silencing observed at the transcript level dose not parallel with the protein expression in MG63 cells. This may be due to the higher mRNA and protein expression in MG63 cells. DEPTOR knockdown strongly inhibited the proliferation of OS cells, according to the CCK- 8 and colony formation assays in vitro. These results are consistent with Parvani et al's findings that DEPTOR deficiency inhibits the growth of breast cancer cells. ${ }^{40}$ The growth of T-ALL cells is also slowed down by DEPTOR depletion. Moreover, Akt knockdown completely abrogates DEPTOR-induced cell proliferation. ${ }^{20}$

Migration and VM formation abilities are essential for OS initial metastasis and relapse..$^{42}$ Invasion capacity also plays an important role in the progress of OS. Indeed, VM formation ability in OS is a poor prognostic factor. ${ }^{23}$ In our study, the migration and invasion ability of OS cells were greatly inhibited by DEPTOR knockdown, as shown by wound healing, Transwell migration, and Transwell invasion assays. DEPTOR depletion abolished VM formation ability, as shown by the tube formation assay. A similar trend was observed in patients with differentiated thyroid carcinoma and breast cancer. Pei et al demonstrated that DEPTOR upregulation was associated with lymph node invasion and distant metastasis. ${ }^{19}$ A previous study indicated that high level of DEPTOR expression was necessary for pulmonary metastasis of triple-negative breast cancers and that re-expression of DEPTOR accelerates efficient outgrowth. ${ }^{40}$
Consequently, we assessed OS cell apoptosis and cell cycle by flow cytometry. DEPTOR downregulation induces cell cycle arrest after epithelial-mesenchymal transition in breast cancer at sites of metastasis. ${ }^{40}$ Increasing evidence also supports that mTORC1 and mTORC2 activation induces apoptosis in MM cell lines. ${ }^{43}$ Moreover, the absence of DEPTOR is sufficient to trigger caspasedependent apoptosis. ${ }^{44} \mathrm{Hu}$ et al demonstrated that DEPTOR depletion produced dramatic apoptosis in HPB-ALL and MOLT4 cells because of higher levels of cleaved caspase-3 and poly ADP-ribose polymerase, while it scarcely affected cell cycle arrest. ${ }^{20}$ Consistently, we found that DEPTOR silencing induced cell cycle arrest in the G0/G1 phase and affected apoptosis in OS cells. However, DEPTOR knockdown inhibits Akt activation, which modulates the function of many substrates involved in cell growth and cell cycle progression. ${ }^{45,46}$ These results also agree with the Srinivas et al's deduction, indicating that DEPTOR depletion leads to apoptotic decision in cervical squamous cell carcinoma. ${ }^{6}$

Functions of DEPTOR are mainly based on its interaction with the mTOR pathway. This study reveals that DEPTOR presents oncogenic properties in OS cells. Thus, we hypothesized that DEPTOR overexpression promotes OS cell survival and progression by sustaining the PI3K/Akt pathway activation. Specifically, DEPTOR overexpression results in inhibiting mTORC1, relieving the mTORC1 feedback suppression on the PI3K signaling pathway, thereby triggering Akt contemporarily. As expected, our results demonstrated that DEPTOR silencing upregulated 4E-BP1 and p-4E-BP1, which indicated the activation of $\mathrm{mTORC} 1$. Furthermore, the expression levels of Akt, p-Akt, and PI3K were reduced to various degrees. Especially, the decreased phosphorylation of Akt at S473 indicated the downregulation of mTORC2 activity. ${ }^{5}$ DEPTOR behaves like an oncogene. Its overexpression indirectly activates Akt by inhibiting mTORC1; thus, DEPTOR downregulation leads to the inhibition of Akt and p-Akt, as well as OS cell death. ${ }^{5}$ Recent studies revealed that DEPTOR expression is under a tight regulation, involving diverse mechanisms, including transcriptional and posttranscriptional regulation, which may explain the controversial phenomena in different cell types and environments. ${ }^{39}$

\section{Limitations}

This study presents some limitations. Further studies are warranted to determine the diagnostic and prognostic value of DEPTOR in patients with OS, as we only collected five pairs of OS tissues and the corresponding adjacent benign tissues and no specific clinical survival data were collected. Future studies are warranted to understand the 
mechanisms underlying DEPTOR regulation and to observe the therapeutic effect of DEPTOR depletion in combination with different drugs in different OS cell types and animal models as well as in clinical studies with a high number of clinical specimens, including the specimens from patients with OS who present with chemoresistance.

\section{Conclusion}

In conclusion, this is the first study investigating the vital function of DEPTOR in human OS. Our results indicate that DEPTOR overexpression is necessary for the proliferation, migration, invasion, and formation of VM and the survival of OS cells. In addition, DEPTOR knockdown notably activates $\mathrm{mTOR}$ and inhibits the PI3K/Akt pathway in OS cells. Our findings indicate that DEPTOR may be an innovative therapeutic target for OS.

\section{Acknowledgment}

This work was supported by the National Natural Science Foundation of China under Grant No 81572203 to Zengwu Shao.

\section{Disclosure}

The authors report no conflicts of interest in this work.

\section{References}

1. Wu S, Du X, Wu M, Du H, Shi X, Zhang T. MicroRNA-409-3p inhibits osteosarcoma cell migration and invasion by targeting catenin-delta1. Gene. 2016;584(1):83-89.

2. O'Day K, Gorlick R. Novel therapeutic agents for osteosarcoma. Expert Rev Anticancer Ther. 2009;9(4):511-523.

3. Xie $\mathrm{CH}$, Cao YM, Huang Y, et al. Long non-coding RNA TUG1 contributes to tumorigenesis of human osteosarcoma by sponging miR-9-5p and regulating POU2F1 expression. Tumour Biol. 2016;37(11): 15031-15041.

4. Subbiah V, Wagner MJ, McGuire MF, et al. Personalized comprehensive molecular profiling of high risk osteosarcoma: implications and limitations for precision medicine. Oncotarget. 2015;6(38):40642-40654.

5. Peterson TR, Laplante M, Thoreen CC, et al. DEPTOR is an mTOR inhibitor frequently overexpressed in multiple myeloma cells and required for their survival. Cell. 2009;137(5):873-886.

6. Srinivas KP, Viji R, Dan VM, et al. DEPTOR promotes survival of cervical squamous cell carcinoma cells and its silencing induces apoptosis through downregulating PI3K/AKT and by up-regulating p38 MAP kinase. Oncotarget. 2016;7(17):24154-24171.

7. Wang C, Yu JT, Miao D, Wu ZC, Tan MS, Tan L. Targeting the mTOR signaling network for Alzheimer's disease therapy. Mol Neurobiol. 2014;49(1):120-135.

8. Dann SG, Selvaraj A, Thomas G. mTOR Complex1-S6K1 signaling: at the crossroads of obesity, diabetes and cancer. Trends Mol Med. 2007;13(6):252-259.

9. Ding L, Congwei L, Bei Q, et al. mTOR: an attractive therapeutic target for osteosarcoma? Oncotarget. 2016;7(31):50805-50813.

10. Gordon IK, Ye F, Kent MS. Evaluation of the mammalian target of rapamycin pathway and the effect of rapamycin on target expression and cellular proliferation in osteosarcoma cells from dogs. Am J Vet Res. 2008;69(8):1079-1084.
11. Lee DH, Qi J, Bradner JE, et al. Synergistic effect of JQ1 and rapamycin for treatment of human osteosarcoma. Int J Cancer. 2015;136(9): 2055-2064.

12. Duan S, Skaar JR, Kuchay S, et al. mTOR generates an auto-amplification loop by triggering the betaTrCP- and CK1alpha-dependent degradation of DEPTOR. Mol Cell. 2011;44(2):317-324.

13. Wang Z, Zhong J, Inuzuka H, et al. An evolving role for DEPTOR in tumor development and progression. Neoplasia. 2012;14(5):368-375.

14. Ji YM, Zhou XF, Zhang J, et al. DEPTOR suppresses the progression of esophageal squamous cell carcinoma and predicts poor prognosis. Oncotarget. 2016;7(12):14188-14198.

15. Li H, Sun GY, Zhao Y, et al. DEPTOR has growth suppression activity against pancreatic cancer cells. Oncotarget. 2014;5(24): 12811-12819.

16. Lai EY, Chen ZG, Zhou X, et al. DEPTOR expression negatively correlates with mTORC1 activity and tumor progression in colorectal cancer. Asian Pac J Cancer Prev. 2014;15(11):4589-4594.

17. Zhou X, Guo J, Ji Y, et al. Reciprocal negative regulation between EGFR and DEPTOR plays an important role in the progression of lung adenocarcinoma. Mol Cancer Res. 2016;14(5):448-457.

18. Rogers-Broadway KR, Chudasama D, Pados G, et al. Differential effects of rapalogues, dual kinase inhibitors on human ovarian carcinoma cells in vitro. Int J Oncol. 2016;49(1):133-143.

19. Pei L, Xie P, Zhou E, Yang Q, Luo Y, Tang Z. Overexpression of DEP domain containing mTOR-interacting protein correlates with poor prognosis in differentiated thyroid carcinoma. Mol Med Rep. 2011; 4(5):817-823

20. $\mathrm{Hu} \mathrm{Y,} \mathrm{Su} \mathrm{H,} \mathrm{Liu} \mathrm{C,} \mathrm{et} \mathrm{al.} \mathrm{DEPTOR} \mathrm{is} \mathrm{a} \mathrm{direct} \mathrm{NOTCH1} \mathrm{target} \mathrm{that}$ promotes cell proliferation and survival in T-cell leukemia. Oncogene. 2017;36(8):1038-1047.

21. Cai X, Liu Y, Yang W, et al. Long noncoding RNA MALAT1 as a potential therapeutic target in osteosarcoma. J Orthop Res. 2016;34(6): 932-941.

22. Song R, Tian K, Wang W, Wang L. P53 suppresses cell proliferation, metastasis, and angiogenesis of osteosarcoma through inhibition of the PI3K/AKT/mTOR pathway. Int J Surg. 2015;20:80-87.

23. Ren K, Yao N, Wang G, et al. Vasculogenic mimicry: a new prognostic sign of human osteosarcoma. Human pathol. 2014;45(10): 2120-2129.

24. Sun B, Zhang D, Zhao N, Zhao X. Epithelial-to-endothelial transition and cancer stem cells: two cornerstones of vasculogenic mimicry in malignant tumors. Oncotarget. 2017;8(18):30502-30510.

25. Tsukumo Y, Alain T, Fonseca BD, Nadon R, Sonenberg N. Translation control during prolonged mTORC1 inhibition mediated by 4E-BP3. Nat commun. 2016;7:11776.

26. Kansara M, Teng MW, Smyth MJ, Thomas DM. Translational biology of osteosarcoma. Nat Rev Cancer. 2014;14(11):722-735.

27. Wullschleger S, Loewith R, Hall MN. TOR signaling in growth and metabolism. Cell. 2006;124(3):471-484.

28. Vanhaesebroeck B, Guillermet-Guibert J, Graupera M, Bilanges B. The emerging mechanisms of isoform-specific PI3K signalling. Nat Rev Mol Cell Biol. 2010;11(5):329-341.

29. Porta C, Paglino C, Mosca A. Targeting PI3K/Akt/mTOR signaling in cancer. Front Oncol. 2014;4:64.

30. Pan Y, Zheng M, Zhong L, et al. A preclinical evaluation of SKLB261, a multikinase inhibitor of EGFR/Src/VEGFR2, as a therapeutic agent against pancreatic cancer. Mol Cancer Ther. 2015;14(2): 407-418.

31. Guertin DA, Sabatini DM. Defining the role of mTOR in cancer. Cancer Cell. 2007;12(1):9-22.

32. Gupte A, Baker EK, Wan SS, et al. Systematic screening identifies dual $\mathrm{PI} 3 \mathrm{~K}$ and mTOR inhibition as a conserved therapeutic vulnerability in osteosarcoma. Clin Cancer Res. 2015;21(14):3216-3229.

33. Lin S, Shao NN, Fan L, Ma XC, Pu FF, Shao ZW. Effect of microRNA101 on proliferation and apoptosis of human osteosarcoma cells by targeting mTOR. J Huazhong Univ Sci Technolog Med Sci. 2014;34(6): 889-895. 
34. Grignani G, Palmerini E, Ferraresi V, et al. Sorafenib and everolimus for patients with unresectable high-grade osteosarcoma progressing after standard treatment: a non-randomised phase 2 clinical trial. Lancet Oncol. 2015;16(1):98-107.

35. Qiu Q, Jiang J, Lin L, et al. Downregulation of RSK2 influences the biological activities of human osteosarcoma cells through inactivating AKT/mTOR signaling pathways. Int $J$ Oncol. 2016;48(6): 2508-2520.

36. Panic N, Larghi A, Amore R, et al. Single nucleotide polymorphisms within the 8Q24 region are not associated with the risk of intraductal papillary mucinous neoplasms of the pancreas. J Gastrointestin Liver Dis. 2016;25(3):311-315.

37. Zhao Y, Xiong X, Sun Y. DEPTOR, an mTOR inhibitor, is a physiological substrate of SCF(betaTrCP) E3 ubiquitin ligase and regulates survival and autophagy. Mol Cell. 2011;44(2):304-316.

38. Luo Z, Yu G, Lee HW, et al. The Nedd8-activating enzyme inhibitor MLN4924 induces autophagy and apoptosis to suppress liver cancer cell growth. Cancer Res. 2012;72(13):3360-3371.

39. Catena V, Bruno T, De Nicola F, et al. Deptor transcriptionally regulates endoplasmic reticulum homeostasis in multiple myeloma cells. Oncotarget. 2016;7(43):70546-70558.
40. Parvani JG, Davuluri G, Wendt MK, et al. Deptor enhances triplenegative breast cancer metastasis and chemoresistance through coupling to survivin expression. Neoplasia. 2015;17(3):317-328.

41. Catena V, Fanciulli M. Deptor: not only a mTOR inhibitor. J Exp Clin Cancer Res. 2017;36(1):12.

42. Jaffe N. Osteosarcoma: review of the past, impact on the future. The American experience. Cancer Treat Res. 2009;152:239-262.

43. Shi Y, Daniels-Wells TR, Frost P, et al. Cytotoxic properties of a DEPTOR-mTOR inhibitor in multiple myeloma cells. Cancer Res. 2016;76(19):5822-5831.

44. Zhang H, Chen J, Zeng Z, Que W, Zhou L. Knockdown of DEPTOR induces apoptosis, increases chemosensitivity to doxorubicin and suppresses autophagy in RPMI-8226 human multiple myeloma cells in vitro. Int J Mol Med. 2013;31(5):1127-1134.

45. Kang HY, Shim D, Kang SS, Chang SI, Kim HY. Protein kinase B inhibits endostatin-induced apoptosis in HUVECs. J Biochem Mol Biol. 2006;39(1):97-104.

46. Han B, Wei W, Hua F, et al. Requirement for ERK activity in sodium selenite-induced apoptosis of acute promyelocytic leukemia-derived NB4 cells. J Biochem Mol Biol. 2007;40(2):196-204.
OncoTargets and Therapy

\section{Publish your work in this journal}

OncoTargets and Therapy is an international, peer-reviewed, open access journal focusing on the pathological basis of all cancers, potential targets for therapy and treatment protocols employed to improve the management of cancer patients. The journal also focuses on the impact of management programs and new therapeutic agents and protocols on

\section{Dovepress}

patient perspectives such as quality of life, adherence and satisfaction. The manuscript management system is completely online and includes a very quick and fair peer-review system, which is all easy to use. Visit http://www.dovepress.com/testimonials.php to read real quotes from published authors. 